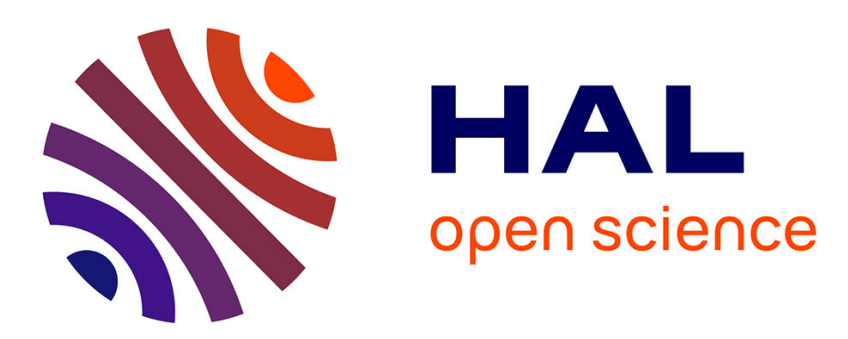

\title{
Fabrication of Buried Co-Planar Metal-Insulator-Metal Nanojunctions with a Gap Lower than $10 \mathrm{~nm}$
}

\author{
V. Rousset, Christian Joachim, S. Itoua, B. Rousset, Nelly Fabre
}

\section{To cite this version:}

V. Rousset, Christian Joachim, S. Itoua, B. Rousset, Nelly Fabre. Fabrication of Buried Co-Planar Metal-Insulator-Metal Nanojunctions with a Gap Lower than $10 \mathrm{~nm}$. Journal de Physique III, 1995, 5 (12), pp.1983-1989. 10.1051/jp3:1995243 . jpa-00249432

\section{HAL Id: jpa-00249432 https://hal.science/jpa-00249432}

Submitted on 1 Jan 1995

HAL is a multi-disciplinary open access archive for the deposit and dissemination of scientific research documents, whether they are published or not. The documents may come from teaching and research institutions in France or abroad, or from public or private research centers.
L'archive ouverte pluridisciplinaire HAL, est destinée au dépôt et à la diffusion de documents scientifiques de niveau recherche, publiés ou non, émanant des établissements d'enseignement et de recherche français ou étrangers, des laboratoires publics ou privés. 
Classification

Physics Abstracts

73.40R

\title{
Fabrication of Buried Co-Planar Metal-Insulator-Metal Nanojunctions with a Gap Lower than $10 \mathrm{~nm}$
}

\author{
V. Rousset $\left({ }^{1}\right)$, C. Joachim $\left({ }^{1}\right)$, S. Itoua $\left({ }^{1}\right)$, B. Rousset $\left({ }^{2}\right)$ and N. Fabre $\left({ }^{2}\right)$ \\ ( ${ }^{1}$ ) CEMES-LOE/CNRS, 29 Rue J. Marvig, B.P. 4347, 31055 Toulouse Cedex, France \\ $\left({ }^{2}\right)$ LAAS/CNRS, 7 Avenue du Colonel Roche, 31077 Toulouse Cedex, France
}

(Received 27 June 1995, accepted 22 September 1995)

\begin{abstract}
Résumé. - Un procédé de fabrication est proposé pour obtenir des nanojonctions métalisolant-métal co-planaires d'une largeur d'isolant bien inférieure à $10 \mathrm{~nm}$ en utilisant un masqueur électronique à $20 \mathrm{keV}$ et un "lift-off" à l'or-palladium. Les électrodes de la nanojonction enterrées dans la silice ont une largeur de moins de $100 \mathrm{~nm}$ et sont distantes de $8 \mathrm{~nm}$. En optimisant l'étape de sous gravure, il est possible de conserver de la silice comme isolant entre les électrodes.
\end{abstract}

\begin{abstract}
An improvement of a process to fabricate co-planar metal-insulator-metal nanojunctions is presented to reach a gap length much lower than $10 \mathrm{~nm}$ using a $20 \mathrm{keV}$ e-beam and an AuPd lift-off. The electrodes of the nanojunction are less than $100 \mathrm{~nm}$ in width and are buried in the $\mathrm{SiO}_{2}$ substrate. For the $8 \mathrm{~nm}$ nanojunctions, the gap is still filled with $\mathrm{SiO}_{2}$ if care is taken about the $\mathrm{SiO}_{2}$ etching step of the process.
\end{abstract}

\section{Introduction}

To measure the electrical resistance of a molecular wire, this molecule must be a jumper over a Metal-Insulator-Metal (MIM) junction. There are at least three requirements for such a junction. (a) The separation between the metallic electrodes must be small enough to accommodate the state of the art oligomer length i.e. between 5 to $10 \mathrm{~nm}$ [1]. (b) The molecule jumping over the gap and adsorbed by its ends to the electrodes has to be imaged to detect its presence and orientation without destruction. (c) The electrodes section must be small enough to minimize the direct tunnel current between the electrodes compared to the one through the molecular wire.

(a) and (c) can be fulfilled using modern electron beam nanolithography [2,3]. But (b) is more difficult to address. One popular, and in principle non destructive way to image a single molecule on a surface, is the Scanning Tunneling (STM) or the Atomic Force (AFM) Microscope [4]. For such techniques, the insulating gap between the two electrodes must be filled with some material to planewize the surface. In that way, the AFM or STM tip scanning on the surface of the gap will not be perturbed by the border of the electrodes because of its 
finite radius. Furthermore, the insulating surface of the gap must be flat enough to be able to image the molecule grafted on the nanojunction.

There are two ways to fabricate a co-planar MIM nanojunction with a filled gap: bury the electrodes in the surface of an insulating material or grow some insulating material in the gap between the electrodes already fabricated on the substrate with a standard nanolithography process $[2,3]$. We have shown recently that $30 \mathrm{~nm}$ buried MIM co-planar nanojunctions can be fabricated using an e-beam nanolithography process [5]. In these nanojunctions, the surface of the $\mathrm{SiO}_{2}$ gap was imaged with an AFM, and the surface corrugation was less than $1 \mathrm{~nm}[6]$. We present here a new fabrication process which results in gaps well below $10 \mathrm{~nm}$ which are still buried metallic electrodes.

\section{From $30 \mathrm{~nm}$ to $10 \mathrm{~nm}$ Gaps}

A pixel jump technique was used to fabricate $30 \mathrm{~nm}$ buried co-planar MIM junctions using an e-beam lithography lift-off process [5]. The junction was made, during the e-beam exposure, by stopping the exposure over a distance (measured in pixels length) larger than the e-beam spot diameter. The smaller gaps were obtained by adjusting the electron dose with the polymethylmethacrylate (PMMA) resist development time to play with proximity effects [5]. To bury the electrodes, the $\mathrm{SiO}_{2}$ substrate was etched after the PMMA resist development.

The $30 \mathrm{~nm}$ gaps were fabricated using a pixel length of $18.75 \mathrm{~nm}$ corresponding approximatively to our effective $20 \mathrm{~nm}$ e-beam spot diameter [5]. A simple way to reduce the distance between the two electrodes of the nanojunction is to use the smallest possible pixel length available on our standard Thomson EPG 102 electron pattern generator. For a $12.5 \mathrm{~nm}$ pixel length, the result is presented in Figure 1. Well defined nanojunctions were fabricated down to a gap of $20 \mathrm{~nm}$ in length using the process optimized for a $18.75 \mathrm{~nm}$ pixel length [5]. The only difference was the number of pixels jumped: between 6 to 8 compared to 3 and 4 for a 18.75 $\mathrm{nm}$ pixel length. Notice that for the nanojunction presented in Figure 1, the metallization height was chosen in such a way that the $\mathrm{SiO}_{2}$ in the gap is easily scanned over with an AFM, as shown in Figure 1b. After optimization, the yield of the process was approximatively $20 \%$ for a standard deviation of $20 \mathrm{~nm}$. This large deviation may be attributed to the difficulties of having an homogeneous $\mathrm{SiO}_{2}$ etching rate in the vicinity of the $\mathrm{SiO}_{2}$ gap protected by the PMMA. Often, the $\mathrm{SiO}_{2}$ in the gap between the electrodes is cut as shown in Figure 2.

For the $6.25 \mathrm{~nm}$ smallest possible pixel length available on the standard EPG 102, a 10 $\mathrm{nm}$ gap size is reached as shown in Figure 3. But this length is too small compared to the interferometry stabilization of the EPG 102 which is limited to a $40 \mathrm{~nm}$ precision, enabling this to be achieved reproducibly. In these processes, we have also tried to adjust the metallization in such a way that the electrodes are at the same level as the $\mathrm{SiO}_{2}$ surface in the gap.

\section{Fabrication of Gaps Below $10 \mathrm{~nm}$}

To be able to fabricate gaps below $10 \mathrm{~nm}$ in a reproducible manner, we have first worked on the EPG 102. The optics and the electronics of the interferometer were modified to reach a $3 \mathrm{~nm}$ stabilization precision [ 7 ]. Furthermore, we have decreased the gain of the $x$ and $y$ e-beam scanning control units to reach a $3 \mathrm{~nm}$ minimum pixel length. One negative consequence of such a reduction is that the pixel length is now smaller than the e-beam diameter leading to a large over-exposure of the PMMA resist if our standard process is used [5]. Therefore, a new process was optimized to take advantage of the stabilized EPG 102. 


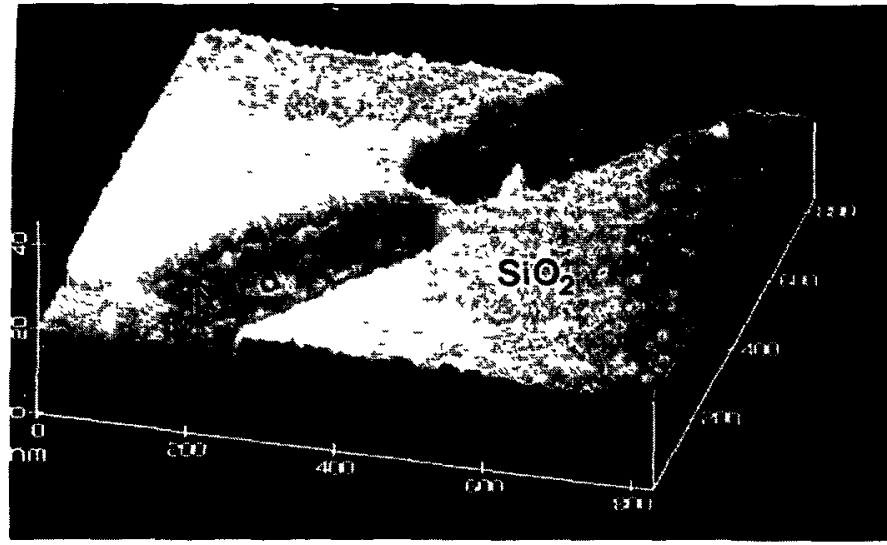

a)

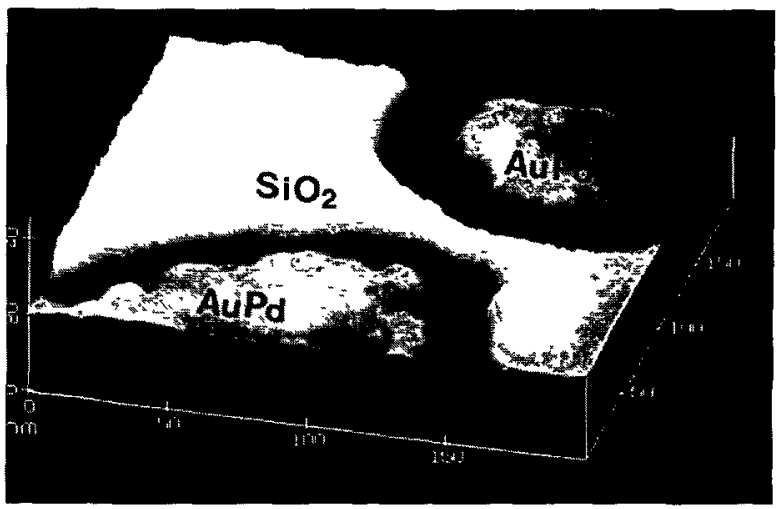

b)

Fig. 1. - a) A 3D view AFM constant force image of a $20 \mathrm{~nm}$ gap in a $100 \mathrm{~nm}$ in width AuPd wire. The image size is $0.8 \times 0.8 \mu \mathrm{m}^{2}$. The metal is recessed by $4 \mathrm{~nm}$ in the $\mathrm{SiO}_{2}$ surface giving a clear access to the $\mathrm{SiO}_{2}$ surface in the gap. b) A 3D view AFM constant force image of a smaller scan in Figure la nanojunction. The image size is $0.2 \times 0.2 \mu \mathrm{m}^{2}$.

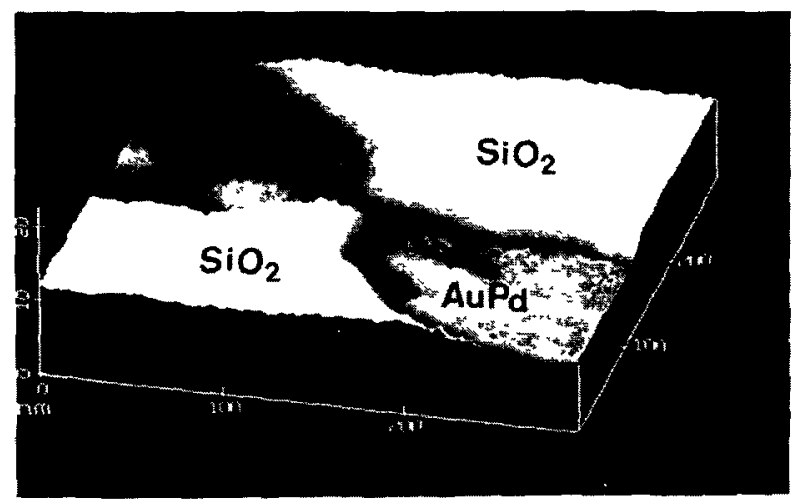

Fig. 2. - A 3D view AFM constant force image of a $20 \mathrm{~nm}$ gap where the $\mathrm{SiO}_{2}$ in the gap was cut by the HF etching. The junction is still there, but there is no longer flat surface in the gap. The image size is $0.3 \times 0.3 \mu \mathrm{m}^{2}$. 


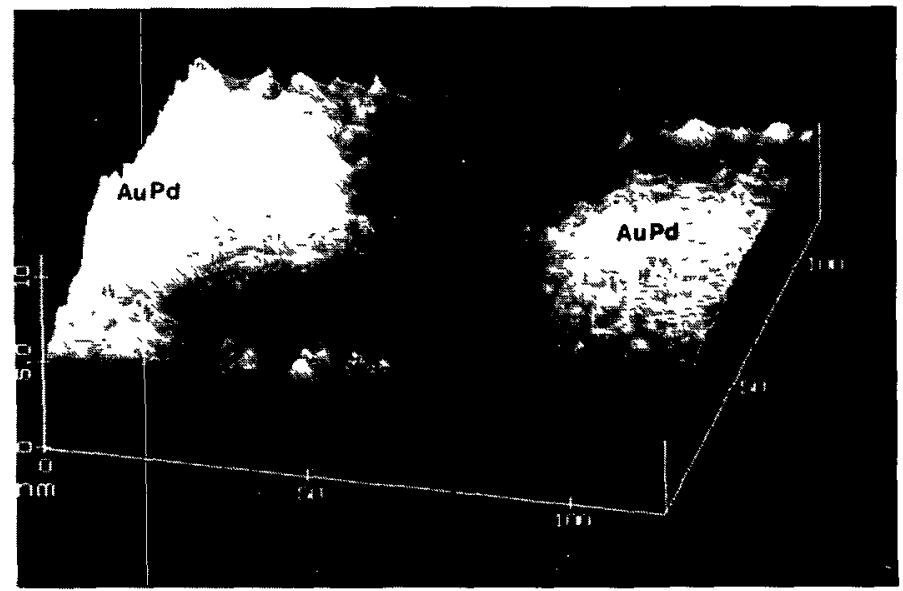

Fig. 3. - A 3D view AFM constant force image of a $10 \mathrm{~nm}$ gap. The $\mathrm{SiO}_{2}$ in the gap is still there. The two pads of the junction are $2.5 \mathrm{~nm}$ higher compared to the $\mathrm{SiO}_{2}$ substrate. The image size is $0.12 \times 0.12 \mu \mathrm{m}^{2}$.

A PMMA resist layer, $50 \mathrm{~nm}$ in thickness, is spin coated on a $\mathrm{Si}(100)$ wafer on which 100 $\mathrm{nm}$ of $\mathrm{SiO}_{2}$ has been thermally grown. The wafer is then baked for $90 \mathrm{~s}$ at $150^{\circ} \mathrm{C}$. For the exposure of this resist, the scanning frequency of the $20 \mathrm{keV}$ e-beam is $300 \mathrm{kHz}$ with a $30 \mathrm{pA}$ beam current and a $20 \mathrm{~nm}$ effective e-beam diameter [5]. This gives a dose of $31.8 \mu \mathrm{C} / \mathrm{cm}^{2}$. This dose is four times smaller than in our previous process [6]. Each pattern is $41 \mu \mathrm{m}$ long and $2 \mu \mathrm{m}$ in width. In the middle, there is a $1 \mu \mathrm{m}$ long and less than $100 \mathrm{~nm}$ in width wire. The gap is fabricated in the middle of the wire. A single e-beam scan is used to expose this wire. Since the elementary pixel length is now $3 \mathrm{~nm}$, the writing field reduces to a $12.0 \times 12.0 \mu \mathrm{m}^{2}$ square divided in $4000 \times 4000$ pixels. This means that the $41 \mu \mathrm{m}$ long pattern must be exposed using five fields instead of one. Due to the increase in stability of the EPG 102, there is however no problem of mismatching between these fields over the whole wafer.

After the exposure, the PMMA is developed with a methylethylketone diluted in ethanol solution for $12 \mathrm{~s}$. The temperature of the solution is held at $19{ }^{\circ} \mathrm{C}$. This short development duration is optimized to compensate pixel overlapping during the exposure of the $100 \mathrm{~nm}$ central wire. The exposure of the $2 \mu \mathrm{m}$ large pads is also realized by exposing only one scan over six to limit the overexposure because the beam diameter is larger than the scanning increment. Then, the wafer is rinsed in an isopropanol solution.

After the development, the $\mathrm{SiO}_{2}$ is etched for $90 \mathrm{~s}$ using a $\mathrm{HF}$ solution held at $20^{\circ} \mathrm{C}$. This etching time has been reduced compared to the standard process [5] to avoid the cut of the $\mathrm{SiO}_{2}$ in the gap as shown in Figure 2. Finally, $10 \mathrm{~nm}$ of AuPd is evaporated on the wafer and lifted off.

The number of pixel jumps in the middle of the exposure of the $100 \mathrm{~nm}$ wire was varied between 12 and 25. Taking into account the e-beam diameter, a jump of 15 pixels of $3 \mathrm{~nm}$ each is at the limit of a gap fabrication. The first gaps appear for a jump of at least 20 pixels. Their length is lower than $10 \mathrm{~nm}$ as shown in Figure 4. But the yield of the process is small, around $5 \%$, corresponding to 8 successful nanojunctions for a fabrication of 150 junctions. For a jump of 25 pixels, the fabricated gaps are comparable in length with the one obtained using a $12.5 \mathrm{~nm}$ pixel length with a jump of 6 to 8 pixels (Fig. 1) with the standard process [5]. 

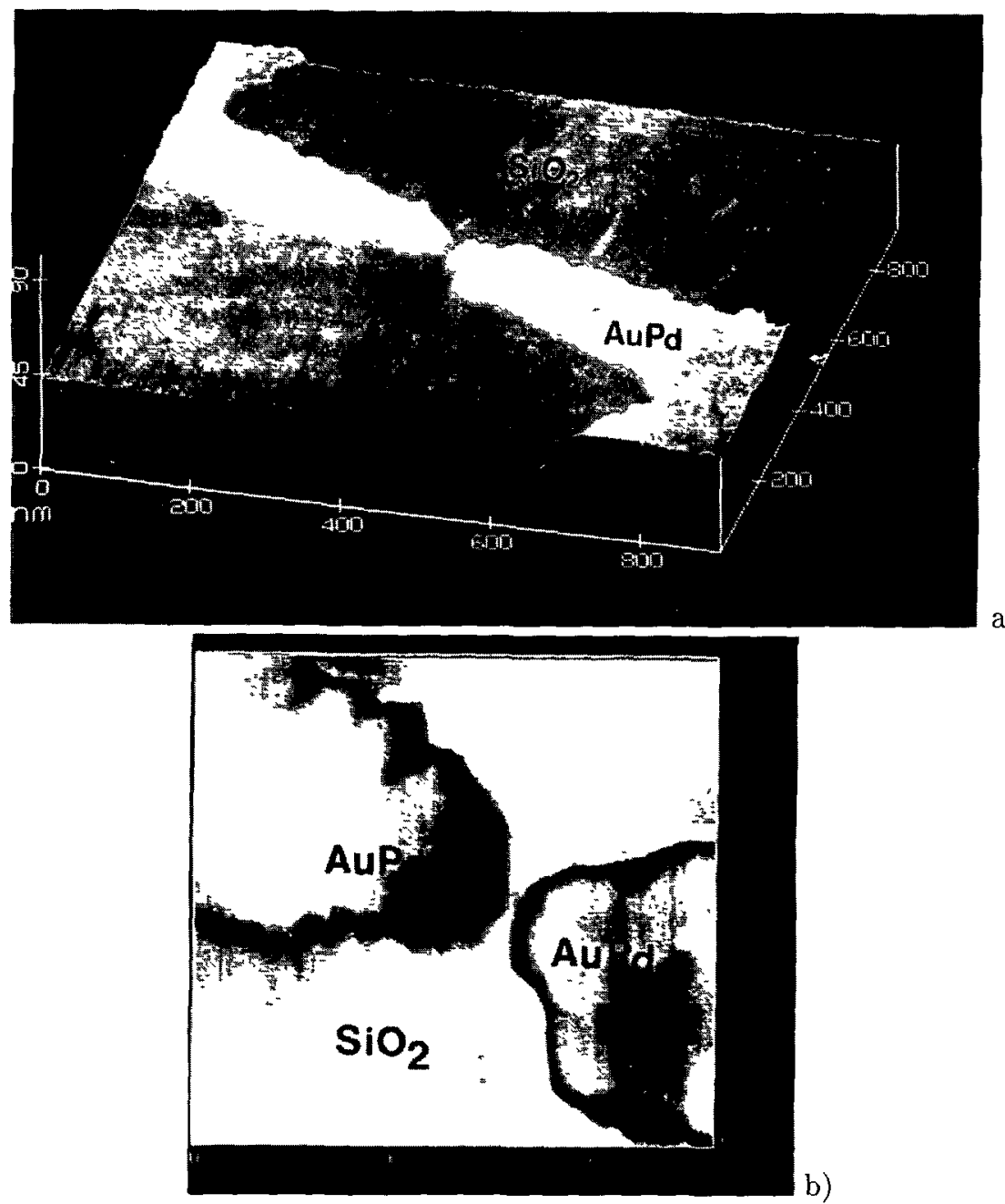

a)

Fig. 4. - a) A 3D view AFM constant force image of a $8 \mathrm{~nm}$ gap where there is still $\mathrm{SiO}_{2}$ in the gap. The two electrodes of the nanojunction are higher by $4.5 \mathrm{~nm}$ compared to the $\mathrm{SiO}_{2}$ substrate. The end of the $2 \mu \mathrm{m}$ in width pads is also imaged. The image size is $0.9 \times 0.9 \mu \mathrm{m}^{2} . \mathrm{b}$ ) A top view of a smaller scan in Figure 4a nanojunction. The end of each electrode is clearly delimited creating a nanojunction with a $8 \mathrm{~nm}$ distance between its electrodes. The image size is $0.25 \times 0.25 \mu \mathrm{m}^{2}$.

The small yield may be attributed to the easy diffusion of the $\mathrm{SiO}_{2}$ etching solution which destabilizes the PMMA resist protecting $\mathrm{SiO}_{2}$ in the gap. Due to the minimal 2 nm diameter of the PMMA molecular size [3], one needs a length of at least, two or three times this diameter to stabilize the PMMA in the gap of the nanojunction.

The AFM characterization of the $8 \mathrm{~nm}$ nanojunction in Figure 4 shows that the electrodes are not totally buried in the $\mathrm{SiO}_{2}$ layer. There is a $4.5 \mathrm{~nm}$ height difference between the top of the electrodes and the $\mathrm{SiO}_{2}$ surface. This is due to the small HF etching duration chosen to protect $\mathrm{SiO}_{2}$ in the gap. If a standard $120 \mathrm{~s}$ etching time is used, the electrodes are buried but there is no $\mathrm{SiO}_{2}$ in the gap as shown in Figure 5 . 

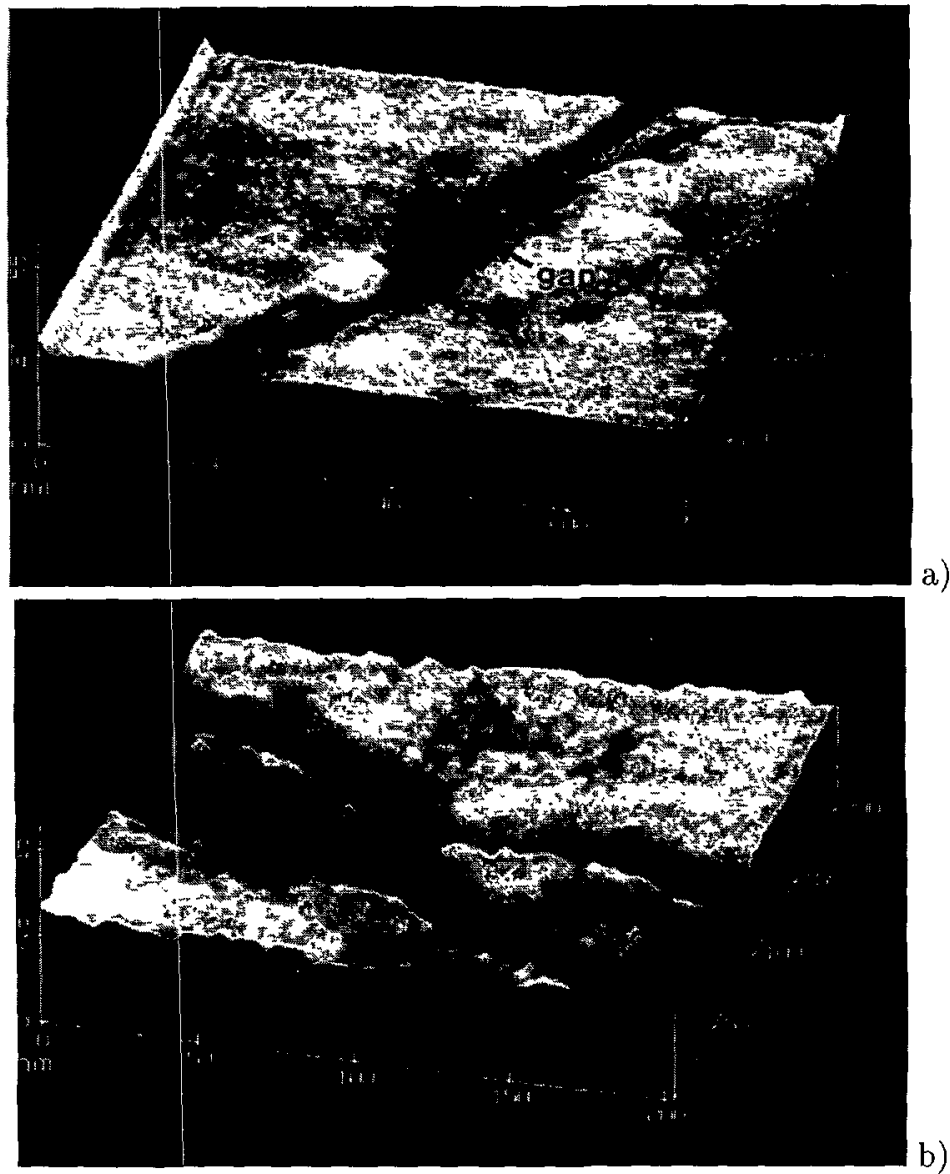

Fig. 5. - a) A 3D view AFM constant force image of a $8 \mathrm{~nm}$ gap fabricated with the electrodes fully buried in the $\mathrm{SiO}_{2}$ surface. The image size is $0.7 \times 0.7 \mu \mathrm{m}^{2}$. b) A 3D view of a smaller scan in the center of the Figure 5a nanojunction to show the end of the two AuPd electrodes and the missing $\mathrm{SiO}_{2}$ material in the gap. The image size is $0.2 \times 0.2 \mu \mathrm{m}^{2}$.

\section{Conclusion}

An optimizated process has been proposed to fabricate co-planar MIM nanojunctions with a gap length lower than $10 \mathrm{~nm}$ and with the electrodes buried in an insulating surface. Co-planar nanojunctions with a $8 \mathrm{~nm}$ distance between their electrodes have been fabricated on $\mathrm{SiO}_{2}$ and characterized with an AFM. When the $\mathrm{SiO}_{2}$ etching duration is reduced, there is still $\mathrm{SiO}_{2}$ material in the gap. For completely buried electrodes, $8 \mathrm{~nm}$ gaps can be obtained but without $\mathrm{SiO}_{2}$ in the gap. We are currently working to increase the process yield.

\section{Acknowledgments}

We would like to thank the DRET for financial support, the LAAS for its kind hospitality during this work and J.P. Martinez for interesting discussions. 


\section{References}

[1] Bäuerle P., Fischer T., Bildlingmeier B., Stabel A. and Rabe J.P., Oligothiophene, Yet Longer? Synthesis, Characterization and Scanning Tunneling Microscopy Images of Homologous, Isomerically Pure Oligo(alkylthiophene)s, Ang. Chem, Int. Ed. EngI. 34 (1995) 303.

[2] Fisher P.B. and Chou S.Y., $10 \mathrm{~nm}$ electron beam lithography and sub-50 $\mathrm{nm}$ overlay using a modified scanning electron microscope, Appl. Phys. Lett. 62 (1993) 2989.

[3] Chen W. and Ahmed H., Fabrication of 5-7 nm wide etched lines in silicon using $100 \mathrm{keV}$ electron beam lithography and polymethylmethacrylate resist, Appl. Phys. Lett. 62 (1993) 1499.

[4] "Scanning Tunneling Microscopy", H.J. Guntherodt and R. Wiesendanger Eds., Springer series in Surface Sciences, Vol. 20 (Springer Verlag, Berlin, 1994).

[5] Itoua S., Joachim C., Rousset B. and Fabre N., Fabrication and AFM characterization of a coplanar tunnel junction with less than $30 \mathrm{~nm}$ interelectrode gap, Nanotechnology 5 (1994) 19.

[6] Itoua S., Joachim C., Rousset B. and Fabre N., Fabrication of $30 \mathrm{~nm}$ inter-electrodes gap co-planar tunnel junctions with buried electrodes, J. Phys. III France 4 (1994) 929.

[7] The modifications of the EPG 102 electron pattern generator from Thomson equiped with a Cameca electron beam column were worked out by ELISA. 